\title{
AVALIAÇÃO DE DESEMPENHO TÉRMICO DE EDIFICAÇÃO PÚBLICA EM CUIABÁ, MT: ESTUDO DE CASO
}

\author{
Nadine Lessa Figueiredo Campos ${ }^{1}$, Marta Cristina de Jesus Albuquerque Nogueira ${ }^{2}$, \\ José Antonio Lambert ${ }^{3}$, Luciane Cleonice Durante ${ }^{4}$ \\ ${ }^{1}$ Arquiteta e Urbanista, Mestre em Engenharia de Edificações e Ambiental/FAET/UFMT. \\ nadine lessa@hotmail.com \\ ${ }^{2}$ Doutorado, Programa de Pós-Graduação em Engenharia de Edificações e Ambiental/ FAET/ UFMT. \\ mcjanp@gmail.com \\ ${ }^{3}$ Doutorado, Programa de Pós-Graduação em Engenharia de Edificações e Ambiental/ FAET/ UFMT. \\ lambert@ufmt.br \\ ${ }^{4}$ Doutorado, Departamento de Arquitetura e Urbanismo/ FAET/ UFMT. \\ luciane.durante@hotmail.com
}

\section{RESUMO}

Considerando o cenário mundial de escassez de recursos naturais, a criação de soluções de consumo de energia mais responsáveis se torna imprescindível. O projeto arquitetônico adequado ao clima permite minimizar o consumo de energia elétrica na fase de uso da edificação. Visando redução no consumo energético das edificações foram desenvolvidas normas de desempenho e eficiência energética em vários países. Neste contexto, este trabalho tem como objetivo geral avaliar o desempenho térmico de uma edificação pública localizada na cidade de Cuiabá, MT. Para tanto, fez-se medições in loco, avaliação de conforto térmico pelo método de Fanger, avaliação da envoltória pelo RTQ-C. A edificação apresentou bom desempenho térmico em suas avaliações, mantendo-se na zona de conforto durante todo o horário de expediente. Espera-se que, com este trabalho, o Regulamento e sua aplicação possam ser difundidos na cidade de Cuiabá, demonstrando sua eficácia e contribuindo para uma melhor eficiência energética das edificações locais, especialmente para prédios públicos.

Palavras- Chave: Desempenho termo - energético, conforto térmico, eficiência energética.

\section{ABSTRACT}

Considering the global scenario of scarce natural resources, creating solutions for more responsible energy consumption becomes essential. The architectural design appropriate to the climate minimizes the energy consumption during use of the building. Aiming at reducing the energy consumption of buildings were developed performance standards and energy efficiency in various countries. In this context, this study aims at evaluating the thermal performance of a public building in the city of Cuiabá, MT. To this end, measurements were made on the spot assessment of thermal comfort by the method of Fanger, evaluation of the envelope by RTQ-C. The building had a good thermal performance in their evaluations, staying in the comfort zone during all business hours. It is hoped that with this work, Regulation and its application can be broadcast in the city of Cuiabá, demonstrating its effectiveness and contributing to improved energy efficiency of local buildings, especially for public buildings.

Keywords: Energy Thermal Performance, thermal comfort, energy efficiency. 


\section{INTRODUÇÃO}

As iniciativas relacionadas à redução do consumo de energia e aos métodos de sua avaliação foram impulsionadas pela crise do petróleo na década de 70 , inserindo a dimensão ambiental na base das preocupações mundiais. Esse processo desencadeou um plano de ação global, visando o equilíbrio entre as necessidades econômicas, sociais e os recursos naturais. A indústria da construção participa ativamente nesse processo ao ser responsável por $40 \%$ do consumo de energia mundial (KLÜSENER, 2009).

As edificações são responsáveis por grande parte do consumo da energia produzida mundialmente. Os sistemas de iluminação e o condicionamento de ar consomem parcela considerável da energia elétrica das edificações do setor residencial, público e comercial, cuja participação no consumo total de energia elétrica no Brasil, é bastante significativa. A tendência de crescimento verificada e estimada é ainda maior, sobretudo, devido à estabilidade da economia, aliada a uma política de melhor distribuição de renda, o que permite o acesso de uma fatia cada vez maior da população aos confortos proporcionados pelas novas tecnologias.

Grande parte das edificações desperdiça considerável parcela de energia elétrica para obtenção de conforto ambiental devido a não incorporação em seus projetos, dos importantes avanços ocorridos nas áreas da arquitetura bioclimática, materiais e tecnologias construtivas adequadas.

Esta pesquisas tem como objetivo avaliar o desempenho térmico de uma edificação pública localizada na cidade de Cuiabá- MT. Para tanto, foram efetuadas: medições in loco da temperatura do ar, temperatura radiante e umidade relativa dos ambientes analisados, análise de conforto ambiental pelo método de Fanger e avaliação da envoltória pelo RTQ-C.

Sob o ponto de vista ambiental, o conforto é definido como o estado mental que expressa à satisfação do homem com o meio ambiente térmico que o circunda (LAMBERTS et al., 2011).

Para Fanger (1972) a definição de conforto é: “...o estado térmico para determinado ambiente, com relação às suas variáveis físicas, quando um menor número de pessoas estejam insatisfeitas com o mesmo". A norma International Organization of Standardization/ ISO-7730 (1984), define-o como: “...estado que expressa satisfação com o ambiente térmico". Já a Norma Brasileira NBR-15220-3(ABNT, 2005), o define como: “... a satisfação psicofisiológica de um indivíduo com as condições térmicas do ambiente".

O desempenho de um edifício está diretamente relacionado com as características dos elementos que o envolvem e suas interações entre o meio exterior e interior. A envoltória é o ponto de partida para a determinação da eficiência energética e para a necessidade de sistemas de aquecimento, resfriamento e ventilação. As cargas condicionadas pelo clima são dinâmicas e aproximadamente periódicas, uma vez que tendem a se repetir em ciclos diários. A principal parte da carga pela envoltória é proporcional à diferença de temperaturas de bulbo seco entre o interior e o exterior (BERALDO, 2006).

A forma arquitetônica é determinante quanto à quantidade de radiação solar, luz natural e ventilação recebida pelo edifício (SILVA, 2007). A intensidade de radiação solar transferida para o interior dependerá da capacidade de conservar calor da envoltória e das características dos materiais de revestimento associadas a sua cor, visto que as propriedades de absorção ou reflexão de um mesmo material podem ser modificadas conforme a cor aplicada (ROMERO, 2001).

Conforme Beraldo (2006) a questão da eficiência das edificações considera que projetos arquitetônicos que durante sua concepção não levam em consideração o clima como um aspecto 
importante, tendem a apresentar más condições de conforto térmico e luminoso. Desta forma, será necessário consumir energia para, por meios alternativos, atingir condições de conforto no interior da edificação. Assim, a edificação mais eficiente será aquela que conseguir atingir ou chegar o mais próximo possível das condições de conforto térmico e luminoso utilizando-se apenas do desenho, das técnicas construtivas e dos materiais.

É função da prática arquitetônica em analisar e estabelecer condições necessárias para avaliação e concepção de ambiente térmico adequado às atividades humanas. "As variáveis arquitetônicas como forma, função, tipos de fechamento e os sistemas de condicionamento (climatização e iluminação) interagem simultaneamente com o meio ambiente e o homem", conforme afirma Lamberts, Dutra e Pereira (2004), sendo assim, apresentam-se como variáveis importantes na elaboração de todo projeto arquitetônico.

As estratégias de projeto da arquitetura bioclimática resgatam a integração da arquitetura com o meio ambiente quando tiram partido do clima, da vegetação, do desenho urbano e das soluções técnicas. Além das variáveis climáticas, deve-se considerar as variáveis humanas e arquitetônicas como forma de se obter o conforto do usuário e a melhoria do desempenho termo energético, tais como:

a) Variáveis arquitetônicas: forma, função, fechamentos opacos, fechamentos transparentes, sombreamento da edificação, cores, sistemas de iluminação, sistemas de aquecimento de água, climatização artificial, carga térmica, sistemas de ventilação natural, resfriamento evaporativo, vegetação, materiais, sistemas de proteção solar, massa térmica dos materiais.

b) Variáveis climáticas: Macroclima - radiação solar, latitude, altitude, vento, massas de ar, temperatura, umidade. Microclima - topografia, vegetação, superfície do solo (natural e construído).

c) Variáveis Humanas: Conforto Térmico - variáveis ambientais, atividade física, vestimenta. Conforto Visual - nível de iluminação, contraste, ofuscamento.

A aplicação de um método brasileiro, desenvolvido considerando peculiaridades regionais e locais, permite contribuir para a implementação e apropriação de uma metodologia que atende às necessidades de redução no consumo de energia e do seu uso eficiente. Os edifícios públicos desempenham papel fundamental para a apropriação e divulgação dessas medidas, na medida em que atingem um público diversificado e amplo. A concretização e viabilização de estratégias de eficiência energética nessas edificações expõem os resultados reais ao usuário.

\section{MATERIAIS E MÉTODO}

\section{1. ÁREA DE ESTUDO: CUIABÁ}

A cidade de Cuiabá é a capital do Estado de Mato Grosso, localizando-se na porção centro-sul do estado, localizado na região Centro-Oeste do Brasil. A cidade encontra-se a uma altitude de 165 metros acima do nível do mar, variando em sua área urbana de 146 a 250 metros. Situa-se na província geomorfológica denominada Depressão Cuiabana, parte integrante da depressão do Rio Paraguai, que consiste numa peneplanície de erosão, onde predominam relevos de baixas amplitudes.

Cuiabá encontra-se na Zona Bioclimática 7. Leão (2007) concluiu, através do relatório elaborado com dados horários do Test Reference Year (TRY), que Cuiabá apresenta 19,5\% de horas de conforto e $80,5 \%$ de desconforto anual, num total de 294 dias avaliados. Sendo que desse 
percentual de horas de desconforto, $75,9 \%$ correspondem-se ao calor e 4,54\% ao desconforto por frio.

Para a correção do calor, a ventilação é proposta como estratégia bioclimática em $56,2 \%$ em nossa capital. As estratégias que podem ser utilizadas em conjunto são resfriamento evaporativo e massa térmica para resfriamento, indicadas em proporções quase equivalentes, com 20,2\% e 19,6\% respectivamente. De acordo com o relatório, a insuficiência das estratégias passivas para o clima de Cuiabá deve ser suprida em $8,55 \%$ das horas de desconforto com condicionamento de ar (LEÃO, 2007).

\subsection{EDIFICAÇÃO ANALISADA}

A edificação analisada possui caráter público, localizada no Centro Político Administrativo (CPA) (Figura 1), situado ao norte do município de Cuiabá, MT. O prédio faz parte de um complexo composto por 3 edificações. Foi analisada apenas uma edificação, pois esta é mais recente, possuindo projeto diferenciado e utilizando sistemas construtivos, sistema de iluminação e refrigeração mais atuais.

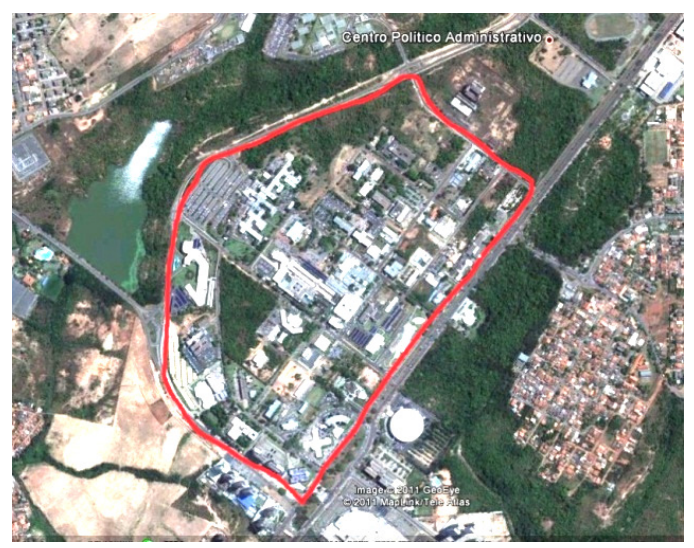

Figura 1: Vista aérea do Centro Político Administrativo de Cuiabá

Fonte: Google Earth

O prédio possui uma área total de $9.547,84 \mathrm{~m}^{2}$, dividida em 3 (três pavimentos). A atividade realizada nas salas é típica de escritórios, sendo feito o uso constante de computadores e manuseio de papéis. O sistema de condicionamento de ar é central, do tipo Chiller, visto que a maior parte do edifício é condicionada.

O partido arquitetônico da edificação é marcado pelos falsos pilares nas fachadas frontal e posterior, que funcionam como sombreamentos horizontais para as grandes faixas de janelas (Figuras 2 a 4). A cor predominante das fachadas é amarelo claro, com alguns detalhes em amarelo escuro.

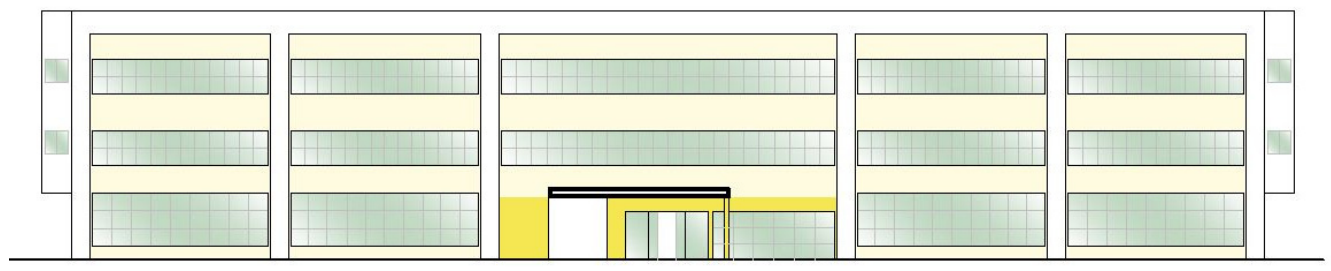

Figura 2: Fachada Frontal (Norte) do Edifício 


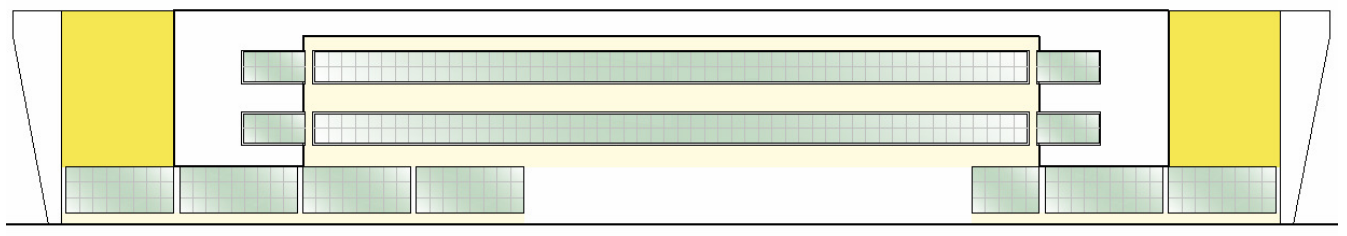

Figura 3: Fachadas Laterais (Leste e Oeste) do Edifício

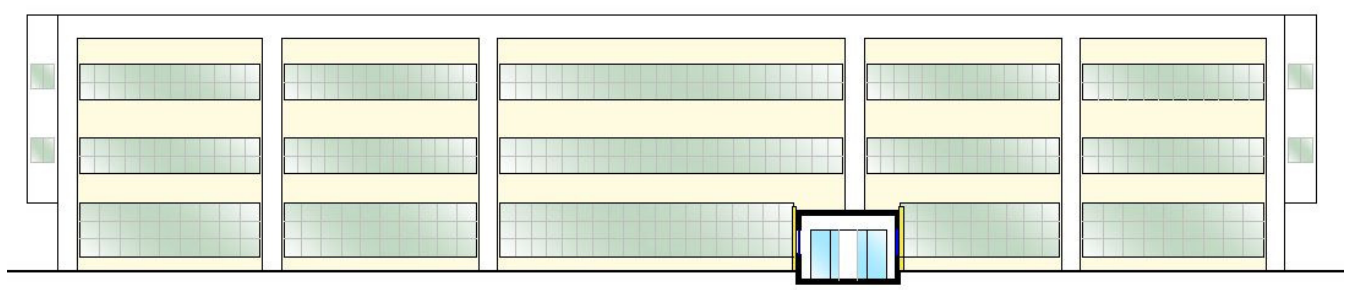

Figura 4: Fachada Posterior (Sul) do Edifício

Os materiais construtivos utilizados são os convencionais habituais da construção civil. As paredes de meia vez foram executadas com tijolos cerâmicos de oito furos, reboco e argamassa. A cobertura é composta por telhas de zinco sobre a laje de concreto do $2^{\circ}$ pavimento. As esquadrias são de alumínio com vidros duplos na cor verde protegidos por película fumê espelhada em toda área envidraçada com a finalidade de reduzir a transferência de radiação solar.

\subsection{EQUIPAMENTOS UTILIZADOS NA COLETA DE DADOS}

Para as medições de temperatura do ar, temperatura de globo, umidade relativa do ar e iluminação in loco foram utilizados termohigrômetros e luxímetros dataloggers ambos acoplados em um único aparelho, da marca Onset, modelo HOBO U12-012 (Figura 5). Para as medições de temperatura de globo, foi adicionado um cabo com sensor de medição de temperatura ao aparelho, sendo que o sensor foi inserido dentro de um globo negro plástico adapto para o sistema de coleta de dados, de forma a substituir o termômetro de globo com esfera de cobre usual (Figura 6).

Alguns estudos realizados por Barbosa, Lamberts e Guths (2008), Navarine et al. (2007), Souza et al. (2002) e Pereira et al. (1967), apresentaram alternativas para a substituição de termômetros de globos negros com esfera de cobre por termômetros de globos negro confeccionado a partir de materiais plásticos. O globo utilizado para as medições desta pesquisa teve sua validade e funcionamento verificados por meio de comparação com o globo negro convencional (esfera de cobre), da marca Instrutherm, já calibrado. Após esta confirmação de eficiência dos globos adaptados foi realizada a calibração destes. 


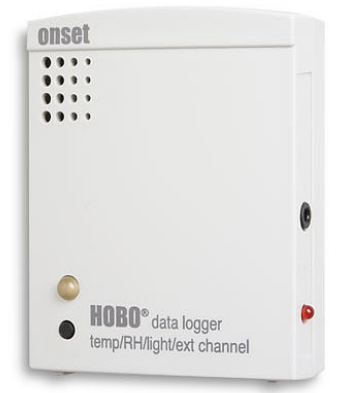

Figura 5: HOBO U12-012, da marca Onset, utilizado para as medições

Fonte: http://www.onsetcompbrasil.com.br

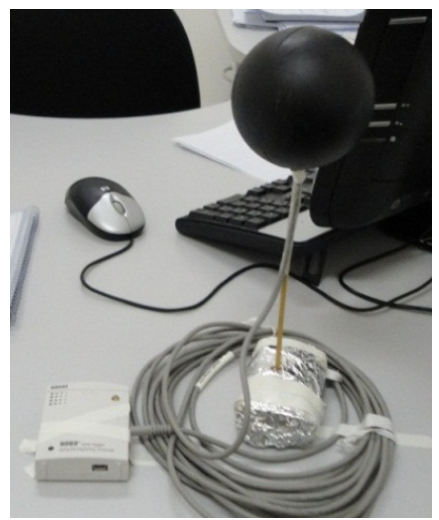

Figura 6: Utilização de Globo negro plástico com datalogger

Para análise de conforto térmico, segundo o método de Fanger foi utilizado o software ANALYSIS CST. O software foi desenvolvido pelo Laboratório de Eficiência Energética em Edificações (LABEEE) da Universidade Federal de Santa Catarina (UFSC).

\subsection{MÉTODO}

\subsubsection{Medições in loco de temperatura}

A edificação foi escolhida inicialmente pelo seu caráter público, outro fator que culminou na escolha do local foi o fato de ser uma edificação recém-construída, com menos de cinco anos de conclusão da obra, o que implicaria o uso iminente de condicionamento de ar, não necessitando adaptações posteriores visando este fim. Trata-se de um partido arquitetônico que não se diferencia muito de outras edificações públicas situadas na mesma região, tendo os mesmos materiais construtivos e uma grande presença de áreas envidraçadas em suas fachadas.

Os dados e informações relativos ao edifício, necessários para a realização do trabalho, foram coletados por meio do projeto arquitetônico, medições in loco e visitas à edificação. As medições têm como objetivo o levantamento de dados para análise do desempenho térmico da edificação. Foram coletados dados de seis ambientes, tendo em média quatro pontos de medição em cada. Os ambientes foram determinados como dois por pavimento, sendo um com aberturas voltadas para a fachada Leste e outro para a fachada Oeste, visto que são os pontos mais críticos de radiação solar.

Foram utilizados 17 dataloggers, com seus respectivos sensores e globos negros, os equipamentos foram colocados sobre as mesas de trabalho dos servidores. 
As medições foram feitas em períodos de 24 horas, com coleta de dados horários. Por se tratar de uma edificação de caráter público onde não há expediente após as 18h, o condicionamento de ar é desligado. Por não haver pessoas trabalhando e todas as aberturas estarem fechadas, as medições de temperatura e umidade em horários sem expediente não foram anexadas aos resultados e nem avaliadas.

\subsubsection{Análise pelo RTQ-C}

A análise da edificação fez-se pelo método prescritivo, conforme especificado pelo RTQ-C e pelo Manual (PROCEL, 2010). Obteve-se a etiqueta parcial da edificação, analisando-se apenas a envoltória.

Inicialmente observou-se se a edificação cumpria os pré-requisitos gerais estabelecidos pelo RTQ-C, para confirmação de que a edificação era elegível à etiquetagem.

Para avaliação da envoltória foi necessário observar se os componentes do edifício cumpriam os pré-requisitos específicos para cada nível almejado. Pré-requisitos estes:

a) Transmitância Térmica da cobertura e das paredes, dados obtidos conforme especificado na NBR 15220 (2003), parte 2. Foi calculada a média das transmitâncias de cada parcela das paredes e cobertura e ponderadas pela área ocupada;

b) Cores e absortância das superfícies: dados especificados na NBR 15220 (2003), parte 2. Será calculada a média das absortâncias de cada parcela das paredes e cobertura e ponderadas pela área ocupada;

Para cálculo do Equivalente Numérico da Envoltória (EqNumEnv), foi calculado o Índice de Consumo da Envoltória, para o qual calcularam-se os itens abaixo especificados conforme o RTQC: Fator Altura (FA), Fator Forma (FF), Percentual de Abertura na Fachada $\left(P A F_{T}\right)$.

Os valores obtidos foram colocados em uma equação especificada pelo RTQ-C para obtenção do Índice de Consumo da Envoltória. Esta equação é definida pela área da edificação e conforme a zona bioclimática em que está inserida.

Comparou-se o Indicador de Consumo obtido a uma escala numérica dividida em intervalos que descrevem um nível de classificação de desempenho que varia de $\mathrm{A}$ a $\mathrm{E}$. A partir desta classificação, obteve-se o Equivalente Numérico da Envoltória conforme o desempenho desta.

\section{APRESENTAÇÃO E ANÁLISE DOS RESULTADOS}

\subsection{Avaliação do Desempenho Térmico da Edificação}

Para a medição foram determinados seis ambientes na edificação a serem medidos, sendo dois por pavimento da edificação, com um na fachada Leste e outro na Oeste, visto que são as fachadas onde a insolação é mais crítica.

Como já mencionado no método, apesar de haver medições de 24 horas, para a análise de conforto térmico utilizou-se apenas os dados relativos à jornada de trabalho, ou seja, oito horas diárias, pois, fora desta não há ocupação ou condicionamento nos ambientes. Todos os resultados apresentados referem-se às medições diurnas, não trabalhando os dados medidos durante o período noturno. 


\subsubsection{Ambiente 1 (Piso térreo)}

A Figura 7 mostra a planta arquitetônica do piso térreo da Edificação de Uso Público destacando, em verde escuro, o Ambiente 1 , setor analisado situado no pavimento térreo do edifício. Neste realizaram-se as medições de temperatura do ar, umidade do ar e temperatura radiante em 4 pontos de medição para avaliação quantitativa (Figura 8).

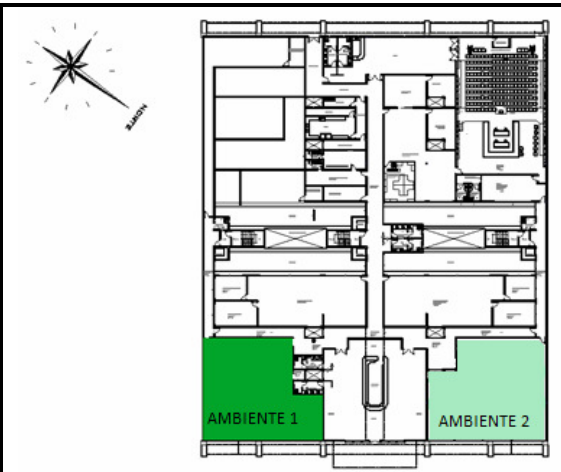

Figura 7: Localização do Ambiente 1 (em verde) no pavimento térreo

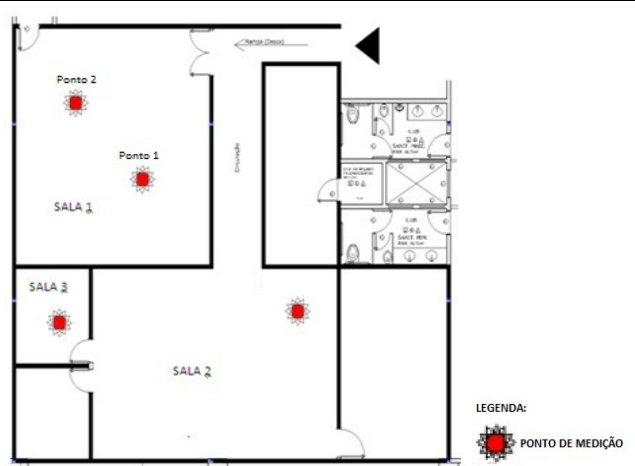

Figura 8: Pontos de medição - Ambiente1 (Piso térreo)

Os valores máximo, mínimo e a média das medições do ambiente 1 podem ser vistos na Tabela 1. A seguir encontra-se a análise do desempenho térmico do ambiente pelo método de Fanger.

TABELA 1: Valores máximos e mínimos dos pontos de medição do Ambiente 1

\begin{tabular}{llllllllllll} 
& Tbs $\left({ }^{\circ} \mathrm{C}\right)$ & Data & Hora & Local & TG $\left({ }^{\circ} \mathbf{C}\right)$ & Data & Hora & Local & U (\%) & Hora & Local \\
\hline Máxima & 25,34 & $17 / 6$ & $15: 00$ & Sala 1, Pto 2 & 29,78 & $16 / 6$ & $15: 00$ & Sala 2 & 61 & $13: 00$ & Sala 3 \\
\hline Mínima & 22,04 & $17 / 6$ & $11: 00$ & Sala 3 & 21,22 & $17 / 6$ & $11: 00$ & Sala 3 & 45,82 & $10: 00$ & Sala 2 \\
\hline Média & 24,15 & & & & 24,04 & & & & 53,44 & \\
\hline
\end{tabular}

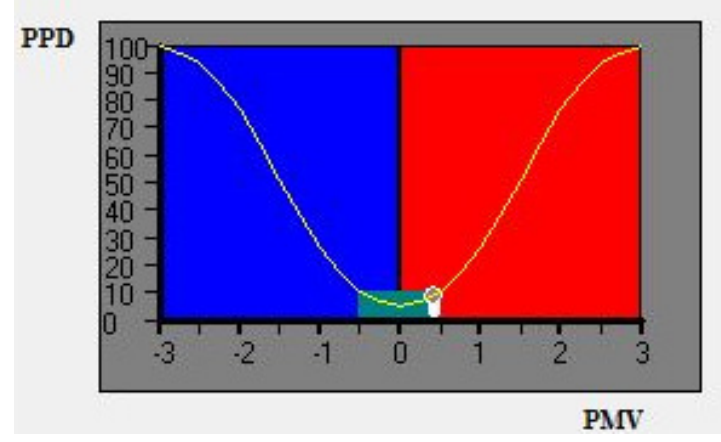

Figura 9: Ambiente 1

Segundo o software Analysis CST (Figura 9) há $8,62 \%$ de pessoas insatisfeitas (PPD) por calor no ambiente 1 e o voto médio predito (PMV) é igual a 0,42. Estes resultados foram obtidos através da média das medições do ambiente 1.

Analisando-se os valores obtidos nas medições e a análise pelo método de Fanger, pôdese constatar que, no ambiente 1 , localizado na face leste, não próximo às aberturas de janelas, 
apresentou-se dentro da zona de conforto recomendada pela norma, assim, proporcionando melhores condições de conforto para os usuários durante a jornada de trabalho.

\subsubsection{Ambiente 2 (Piso Térreo)}

A Figura 10 mostra a planta arquitetônica do piso térreo da edificação de Uso Público destacando, em verde, o Ambiente 2. Neste, destacado em verde, realizaram-se as medições de temperatura do ar, umidade do ar e temperatura radiante em 2 pontos de medição para avaliação quantitativa (Figura 11).
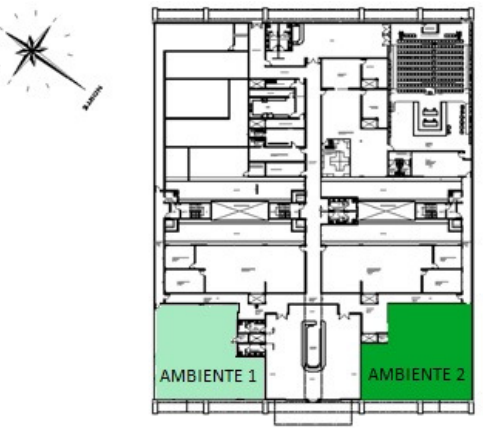

Figura 10: Localização do Ambiente 2 (em verde) no pavimento térreo

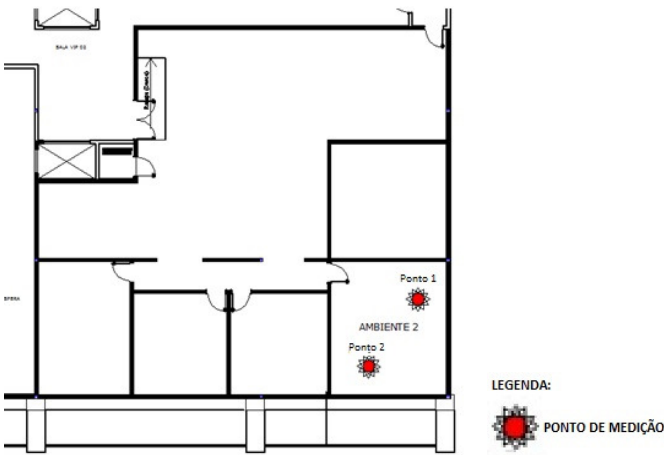

Figura 11: Pontos de medição - Ambiente 2 (Piso térreo)

Os valores máximos, mínimos e as médias das medições do ambiente 2 podem ser vistos na Tabela 2. A seguir encontram-se a análise do desempenho térmico do ambiente pelo método de Fanger.

TABELA 2: Valores máximos e mínimos dos pontos de medição do Ambiente 2

\begin{tabular}{cccccccccccc}
\hline & $\begin{array}{c}\text { Tbs } \\
\left({ }^{\circ} \mathbf{C}\right)\end{array}$ & Data & Hora & Local & TG $\left({ }^{\circ} \mathbf{C}\right)$ & Data & Hora & Local & $\begin{array}{c}\text { U } \\
(\%)\end{array}$ & Hora & Local \\
\hline Máxima & 26,65 & $17 / 6$ & $14: 00$ & Pto 1 & 26,14 & $16 / 6$ & $13: 00$ & Pto 2 & 62,31 & $18: 00$ & Pto 2 \\
\hline Mínima & 21,96 & $16 / 6$ & $17: 00$ & Pto 2 & 21,96 & $16 / 6$ & $17: 00$ & Pto 2 & 38,71 & $15: 00$ & Pto 1 \\
\hline Média & 24,7 & & & & 24,43 & & & & 46,86 & \\
\hline
\end{tabular}

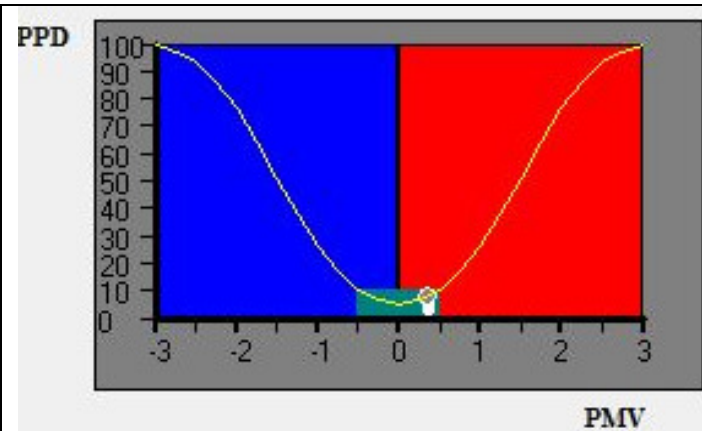

Figura 12: Ambiente 2
Segundo o software Analysis CST (Figura 12) há 7,86\% de pessoas insatisfeitas (PPD) por calor no ambiente 2 e o voto médio predito (PMV) é igual a 0,37. Estes resultados foram obtidos através da média das medições do ambiente 2 . 
Analisando-se os valores obtidos nas medições e a análise pelo método de Fanger, pôdese constatar que, no ambiente 2 , localizado na face oeste, com um ponto de medição locado próximo à abertura de janela, apresentou-se dentro da zona de conforto recomendada pela norma, assim, proporcionando melhores condições de conforto para os usuários durante a jornada de trabalho.

\subsubsection{Ambiente 3 (Piso 1)}

A Figura 13 mostra a planta arquitetônica do primeiro piso da edificação de Uso Público, destacando, em verde escuro, o Ambiente 3, setor analisado. Neste realizaram-se as medições de temperatura do ar, umidade do ar e temperatura radiante em cinco pontos para avaliação quantitativa (Figura 14).

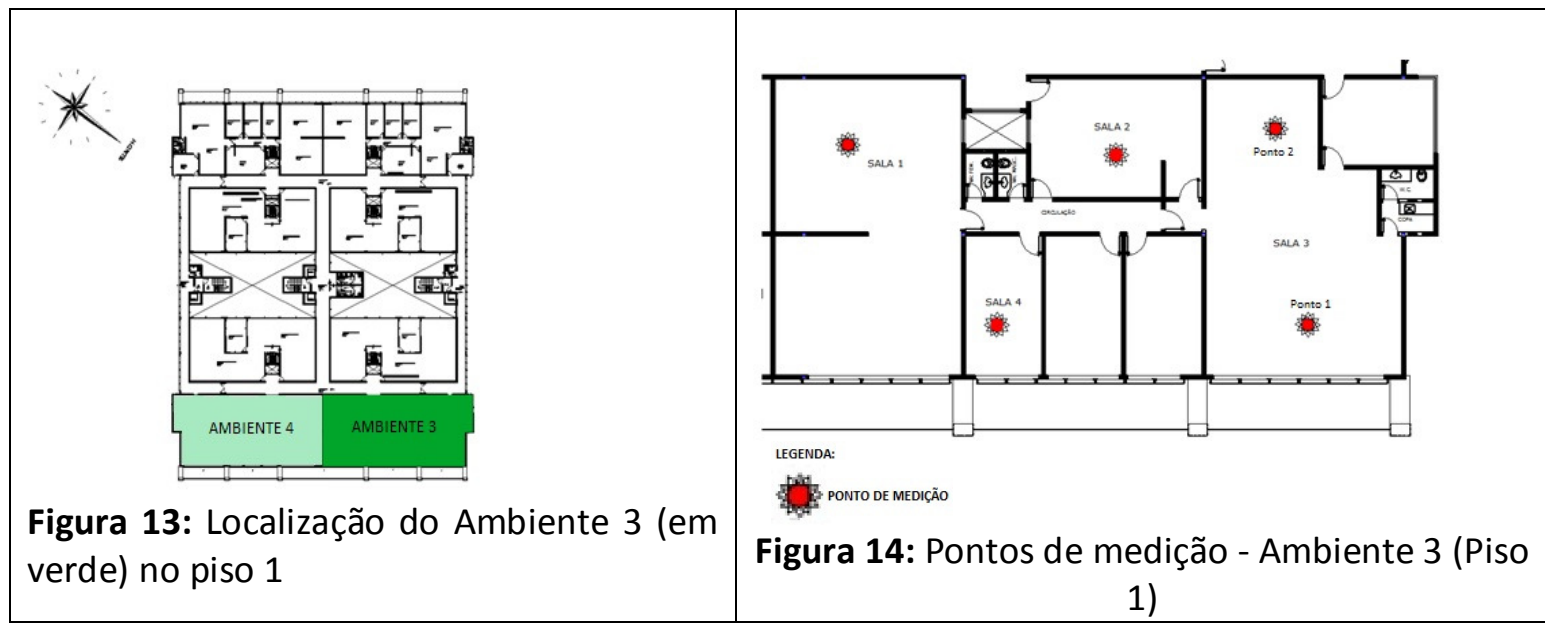

Os valores máximos, mínimos e as médias das medições do ambiente 3 podem ser vistos na Tabela 3. A seguir encontra-se a análise do desempenho térmico do ambiente pelo método de Fanger.

TABELA 3: Valores máximos e mínimos dos pontos de medição do Ambiente 3

\begin{tabular}{|c|c|c|c|c|c|c|c|c|c|c|c|}
\hline & $\begin{array}{l}\text { Tbs } \\
\left({ }^{\circ} \mathrm{C}\right)\end{array}$ & Data & Hora & Local & TG $\left({ }^{\circ} \mathrm{C}\right)$ & Data & Hora & Local & $\begin{array}{c}U \\
(\%)\end{array}$ & Hora & Local \\
\hline Máxima & 24,81 & $15 / 6$ & 18:00 & Sala 4 & 25,03 & $15 / 6$ & 18:00 & Sala 4 & 64,15 & 08:00 & Sala 2 \\
\hline Mínima & 22,47 & $15 / 6$ & $13: 00$ & $\begin{array}{c}\text { Sala } 3 \text {, } \\
\text { Pto } 1\end{array}$ & 21,51 & $15 / 6$ & $18: 00$ & $\begin{array}{c}\text { Sala 3, } \\
\text { Pto2 }\end{array}$ & 48,44 & 09:00 & $\begin{array}{c}\text { Sala } 3 \text {, } \\
\text { Pto } 3\end{array}$ \\
\hline Média & 23,74 & & & & 23,36 & & & & 56,49 & & \\
\hline
\end{tabular}




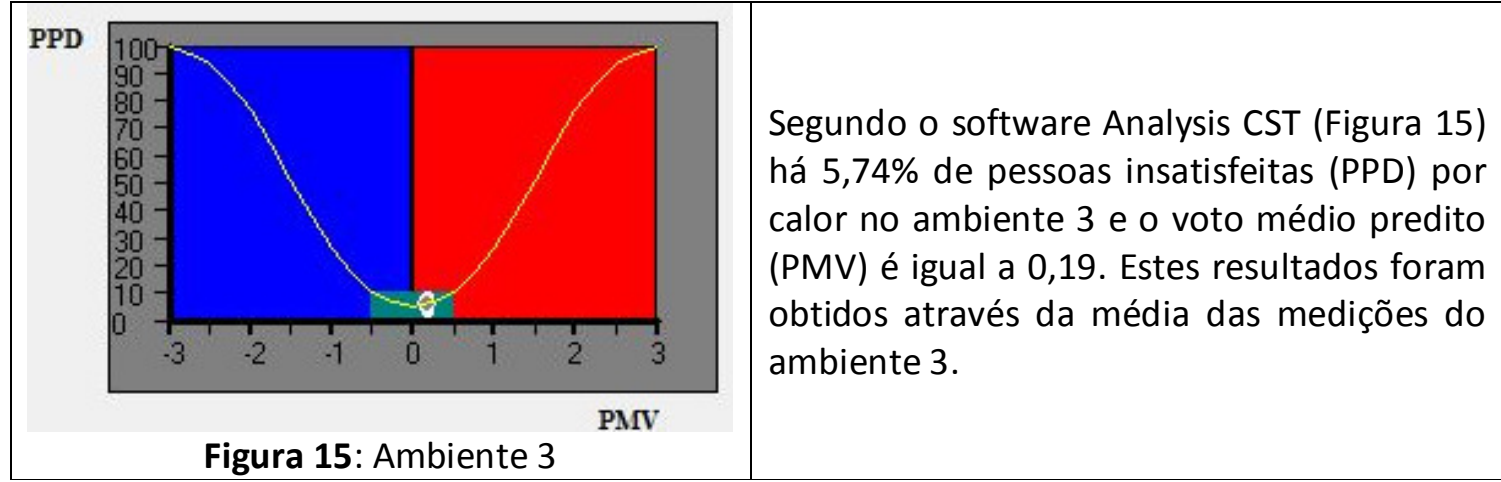

Analisando-se os valores obtidos nas medições e a análise pelo método de Fanger, pôdese constatar que, no ambiente 3, localizado na face oeste, com dois pontos de medição locados próximos às aberturas de janela, apresentou-se dentro da zona de conforto recomendada pela norma, assim, proporcionando melhores condições de conforto para os usuários durante a jornada de trabalho.

\subsubsection{Ambiente 4 (Piso 1)}

A Figura 16 mostra a planta arquitetônica do piso 1, destacando o Ambiente 4. Neste, destacado em verde escuro, realizaram-se as medições de temperatura do ar, temperatura de globo e umidade do ar em dois pontos para avaliação quantitativa (Figura 17).

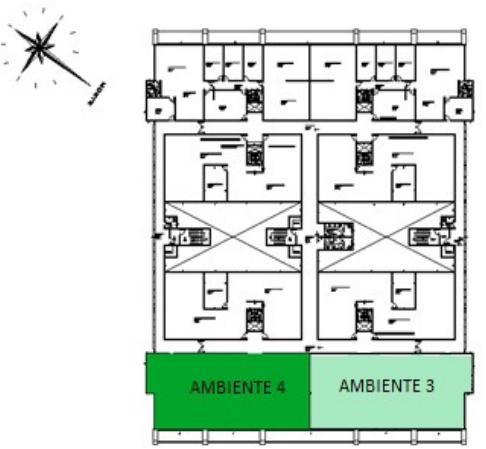

Figura 16: Localização do Ambiente 4 (em verde) no piso 1

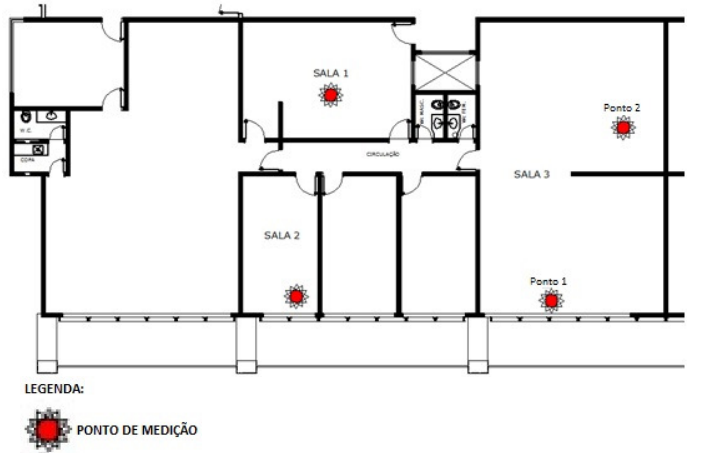

Figura 17: Pontos de medição - Ambiente 4 (Piso 1)

Os valores máximos, mínimos e as médias das medições do ambiente 4 podem ser vistos na Tabela 4. A seguir encontra-se os a análise do desempenho térmico do ambiente pelo método de Fanger. 
TABELA 4: Valores máximos e mínimos dos pontos de medição do Ambiente 4

\begin{tabular}{|c|c|c|c|c|c|c|c|c|c|c|c|}
\hline & $\begin{array}{l}\text { Tbs } \\
\left({ }^{\circ} \mathrm{C}\right)\end{array}$ & Data & Hora & Local & TG $\left({ }^{\circ} \mathrm{C}\right)$ & Data & Hora & Local & $\begin{array}{l}\text { U } \\
\text { (\%) }\end{array}$ & Hora & Local \\
\hline Máxima & 26,18 & $21 / 6$ & $18: 00$ & Sala 2 & 26,03 & $20 / 6$ & $18: 00$ & Sala 2 & 60,08 & $12: 00$ & $\begin{array}{l}\text { Sala 3, } \\
\text { Pto } 2\end{array}$ \\
\hline Mínima & 22,08 & $21 / 6$ & 8:00 & $\begin{array}{c}\text { Sala 3, } \\
\text { Pto } 2\end{array}$ & 20,88 & $21 / 6$ & 08:00 & $\begin{array}{c}\text { Sala 3, } \\
\text { Pto } 2\end{array}$ & 45,91 & $14: 00$ & Sala 2 \\
\hline Média & 24,43 & & & & 24,08 & & & & 53,14 & & \\
\hline
\end{tabular}

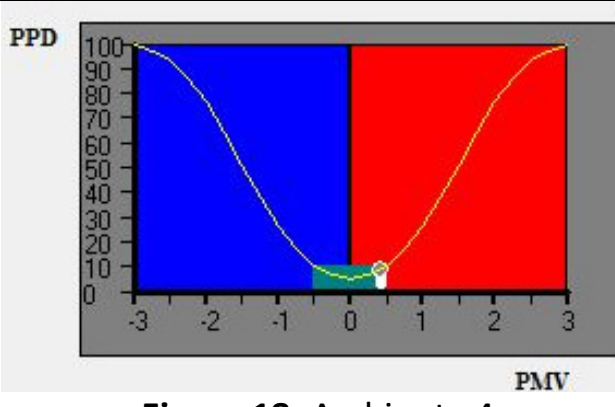

Figura 18: Ambiente 4
Segundo o software Analysis CST (Figura 18 ) há $8,62 \%$ de pessoas insatisfeitas (PPD) por calor no ambiente 4 e o voto médio predito (PMV) é igual a 0,42 . Estes resultados foram obtidos através da média das medições do ambiente 4 .

Analisando-se os valores obtidos nas medições e a análise pelo método de Fanger, pôdese constatar que, no ambiente 4, localizado na face leste, com dois pontos de medição locados próximos às aberturas de janela, apresentou-se dentro da zona de conforto recomendada pela norma, assim, proporcionando melhores condições de conforto para os usuários durante a jornada de trabalho.

\subsubsection{Ambiente 5 (Piso 2)}

A seguir é mostrada, na figura 19, a planta arquitetônica do piso 2 na Edificação de uso Público, ambiente 5 , onde este destacado em verde escuro, sendo o setor medido e os pontos onde realizou as medições de temperatura do ar, temperatura de globo e umidade do ar em 5 pontos de medição para avaliação quantitativa (Figura 20).

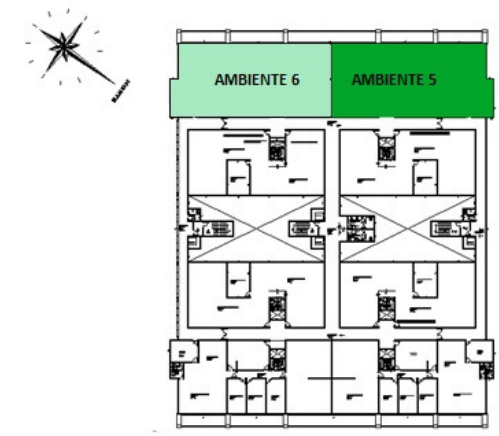

Figura 19: Localização do Ambiente 5 (em verde) no piso 2

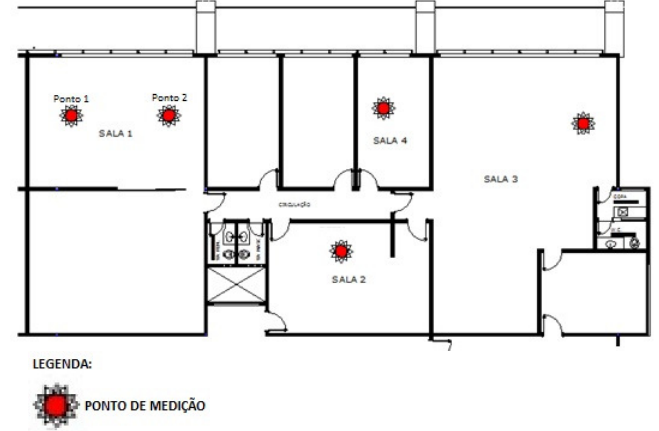

Figura 20: Localização dos pontos de medição Ambiente 5 (Piso 2) 
Os valores máximos, mínimos e as médias das medições do ambiente 5 podem ser vistos na Tabela 5. A seguir encontra-se os a análise do desempenho térmico do ambiente pelo método de Fanger.

TABELA 5: Valores máximos e mínimos dos pontos de medição do Ambiente 5

\begin{tabular}{|c|c|c|c|c|c|c|c|c|c|c|c|}
\hline & $\begin{array}{l}\text { Tbs } \\
\left({ }^{\circ} \mathrm{C}\right)\end{array}$ & Data & Hora & Local & TG $\left({ }^{\circ} \mathrm{C}\right)$ & Data & Hora & Local & $\begin{array}{c}U \\
(\%)\end{array}$ & Hora & Local \\
\hline Máxima & 24,47 & $15 / 6$ & 18:00 & $\begin{array}{c}\text { Sala } 1, \\
\text { Pto } 1\end{array}$ & 24,96 & $15 / 6$ & 18:00 & Sala 3 & 60,86 & $15 / 6$ & $17: 00$ \\
\hline Mínima & 20,59 & $15 / 6$ & 13:00 & Sala 2 & 20,3 & $15 / 6$ & $13: 00$ & Sala 2 & 46,9 & $15 / 6$ & $12: 00$ \\
\hline Média & 22,6 & & & & 22,39 & & & & 53,22 & & \\
\hline
\end{tabular}

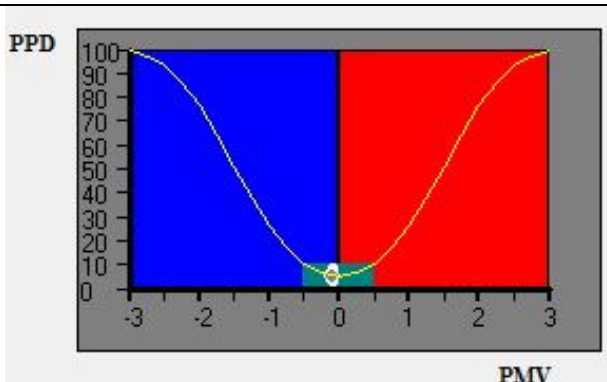

Figura 21: Ambiente 5
Segundo o software Analysis CST (Figura 21) há $5,12 \%$ de pessoas insatisfeitas por frio (PPD) no ambiente 5 e o voto médio predito (PMV) é igual a -0,08.

Analisando-se os valores obtidos nas medições e a análise pelo método de Fanger, pôdese constatar que, no ambiente 5 , localizado na face oeste, não próximo às aberturas de janelas, apresentou-se dentro da zona de conforto recomendada pela norma, assim, proporcionando melhores condições de conforto para os usuários durante a jornada de trabalho.

\subsubsection{Ambiente 6 (Piso 2)}

A Figura 22 mostra a planta arquitetônica do piso 2, destacando em verde, o ambiente 6, setor analisado. Neste, destacado em verde escuro, realizaram- se as medições de temperatura do ar, temperatura de globo e umidade do ar em cinco pontos para avaliação quantitativa (Figura 23).

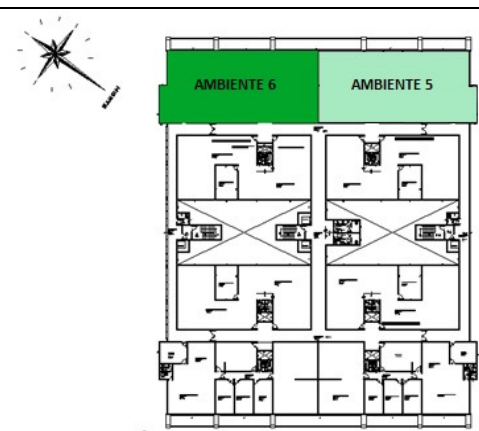

Figura 22: Localização do Ambiente 6 (em verde) no piso 2

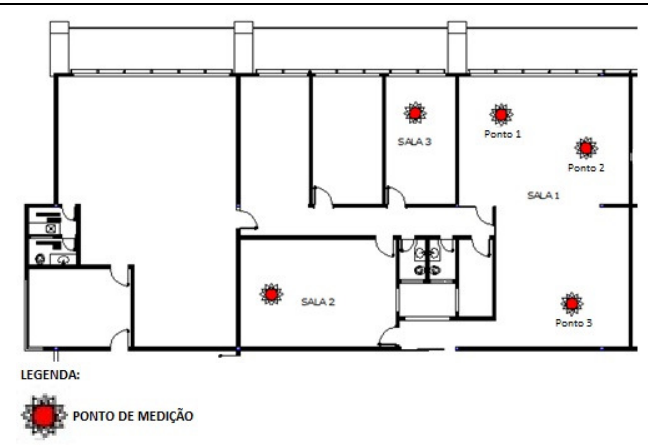

Figura 23: Pontos de Medição - Ambiente 6 (Piso 2) 
Os valores máximos, mínimos e as médias das medições do ambiente 6 podem ser vistos na Tabela 6. A seguir encontra-se a análise do desempenho térmico do ambiente pelo método de Fanger.

TABELA 6: Valores máximos e mínimos dos pontos de medição do Ambiente 6

\begin{tabular}{|c|c|c|c|c|c|c|c|c|c|c|c|}
\hline & $\begin{array}{l}\text { Tbs } \\
\left({ }^{\circ} \mathrm{C}\right)\end{array}$ & Data & Hora & Local & TG $\left({ }^{\circ} \mathrm{C}\right)$ & Data & Hora & Local & $\begin{array}{c}U \\
(\%)\end{array}$ & Hora & Local \\
\hline Máxima & 28,54 & $15 / 8$ & 8:00 & Pto 1 & 28,65 & $12 / 8$ & 18:00 & $\begin{array}{c}\text { Sala } 1, \\
\text { Pto } 1\end{array}$ & 46,19 & $12 / 8$ & $14: 00$ \\
\hline Mínima & 22,3 & $12 / 8$ & 18:00 & $\begin{array}{c}\text { Sala 1, } \\
\text { Pto } 2\end{array}$ & 21,75 & $12 / 8$ & $13: 00$ & $\begin{array}{c}\text { Sala 1, } \\
\text { Pto } 2\end{array}$ & 32,98 & $15 / 8$ & $13: 00$ \\
\hline Média & 25,92 & & & & 25,59 & & & & 38,79 & & \\
\hline
\end{tabular}

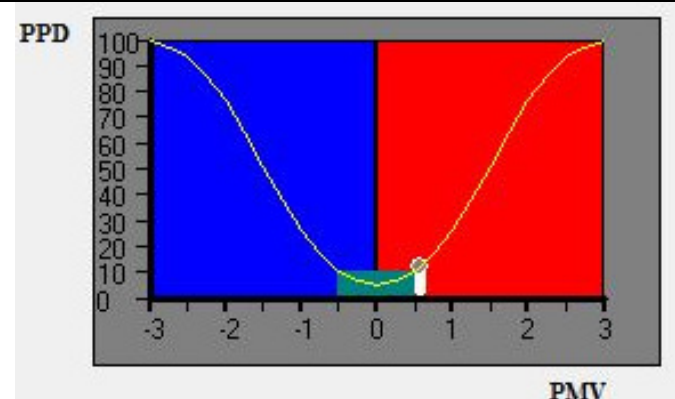

Figura 24: Ambiente 6
Segundo o software Analysis CST (Figura 24) há $11,54 \%$ de pessoas insatisfeitas (PPD) por calor no ambiente 6 e o voto médio predito (PMV) é igual a 0,56. Estes resultados foram obtidos através da média das medições do ambiente 6 .

Analisando-se os valores obtidos nas medições e a análise pelo método de Fanger, pôdese constatar que, no ambiente 6 , localizado na face leste, com dois pontos de medição locados próximos às aberturas de janelas, apresentou-se dentro da zona de conforto recomendada pela norma, assim, proporcionando melhores condições de conforto para os usuários durante a jornada de trabalho.

Após realização das medições e análise dos dados, mesmo com os ambientes voltados para a face oeste e aparelhos locados próximos às aberturas, verificou-se que os valores obtidos ficaram sempre dentro da zona de conforto, isso é decorrente de ser um ambiente de trabalho climatizado e as esquadrias apresentarem películas de proteção contra radiação nos vidros, não apresentando diferença significativa para as fachadas leste e oeste.

\subsection{AVALIAÇÃO DA EDIFICAÇÃO PELO RTQ-C}

\subsubsection{Pré- Requisitos Específicos da Envoltória}

Para determinação da eficiência da envoltória é necessário, inicialmente, o atendimento a pré-requisitos específicos. Estes dizem respeito às características dos materiais construtivos da envoltória com relação à zona bioclimática na qual se insere (no caso, zona 7), são eles:

a) Transmitância Térmica da cobertura $\left(U_{c a b}\right)$ : Melo (2007) especifica para a cobertura $\mathrm{U}=1,06 \mathrm{~W} /\left(\mathrm{m}^{2} \mathrm{~K}\right)$. Para o Regulamento, este valor atinge apenas pré- requisito para o nível $\mathrm{B}$, que exige $\mathrm{U} \leq 1,5 \mathrm{~W} /\left(\mathrm{m}^{2} \mathrm{~K}\right)$ para ambientes condicionados localizados na zona bioclimática 7 . 
b) Transmitância Térmica das paredes externas $\left(U_{\text {par }}\right)$ : por se tratar de paredes convencionais de tijolo cerâmico de oito furos circulares, com reboco e argamassa em ambos os lados, conforme NBR 1522 (2005), parte 2, $U_{\text {par }}=2,28 \mathrm{~W} /\left(\mathrm{m}^{2} . \mathrm{K}\right)$. Esse valor atende ao prérequisito do nível $A$ do Regulamento, que exige um limite máximo de $3,7 \mathrm{~W} /\left(\mathrm{m}^{2} . \mathrm{K}\right)$ para paredes com capacidade térmica superior a $80 \mathrm{~kJ} /\left(\mathrm{m}^{2} . \mathrm{K}\right)$.

c) Capacidade térmica das paredes externas $\left(C_{T}\right)$ : também conforme NBR 1522 (2005), parte 2, para a mesma parede, $C_{T}=168 \mathrm{~kJ} /\left(\mathrm{m}^{2} . \mathrm{K}\right)$

d) Cores e absortância da cobertura $(\propto)$ : Melo (2007) especifica para a cobertura $\propto=0,25$. Para o Regulamento, este valor atende ao pré- requisito para o nível $A$, que exige $\alpha<0,50$ do espectro solar.

e) Cores e absortância das paredes externas ( $*$ : :NBR 1522 (2005), parte 2, aponta para a cor amarela $x=0,3$.Esse valor atende ao pré- requisito do nível $A$ do Regulamento, que exige $x<0,5$.

f) Não há iluminação zenital no edifício, logo, este item não pôde ser avaliado.

\subsubsection{Indicador de Consumo}

$O$ indicador de consumo da envoltória, em decorrência da Zona Bioclimática 7 a qual pertence a edificação e da área de projeção da edificação Ape $>500 \mathrm{~m}^{2}$, foi calculado a partir da Equação 01 do Regulamento:

$\square / C \square_{\Downarrow} e n v=-69,48 . F A+1347,78 . F F+37,74 . \square P A F \square, T+3,03 . F 5-0,13 . A V S-0,19 . A H S+19,25 / F F+0,04 . A H S /((\square P A F \square T . F 5))-306,35$

Eq. 01]

Onde:

ICenv: Indicador de Consumo da envoltória (adimensional);

Ape: Área de projeção do edifício $\left(\mathrm{m}^{2}\right)$;

Atot: Área total de piso construída $\left(\mathrm{m}^{2}\right)$;

Aenv: Área da envoltória $\left(\mathrm{m}^{2}\right)$;

Apcob: Área de projeção da cobertura $\left(\mathrm{m}^{2}\right)$;

AVS: Ângulo Vertical de Sombreamento;

AHS: Ângulo Horizontal de Sombreamento

FF: Fator de Forma, (Aenv/ Vtot);

FA: Fator Altura, (Apcob/ Atot);

FS: Fator Solar dos vidros;

PAFT: Percentual de Abertura na Fachada total (adimensional, para uso na equação);

Vtot: Volume total da edificação $\left(\mathrm{m}^{3}\right)$.

Os valores para o cálculo da equação obtidos da edificação podem ser vistos na Tabela 7. 
Tabela 7: Variáveis para cálculo da equação do Índice de Consumo da Envoltória

\begin{tabular}{cc}
\hline Variável & Edificação \\
\hline Área de projeção do edifício (Ape) & $3.214,33 \mathrm{~m}^{2}$ \\
\hline Área total de piso construída (Atot) & $9.547,87 \mathrm{~m}^{2}$ \\
\hline Área da envoltória (Aenv) & $5.724,37 \mathrm{~m}^{2}$ \\
\hline Área de projeção da cobertura (Apcob) & $3.214,33 \mathrm{~m}^{2}$ \\
\hline Ângulo Vertical de Sombreamento (AVS) & $85,76^{\circ}$ \\
\hline Ângulo Horizontal de Sombreamento (AHS) & $24,12^{\circ}$ \\
\hline Fator de Forma (mínimo) (FF) & 0,17 \\
\hline Fator Altura (FA) & 0,34 \\
\hline Fator Solar (FS) & 0,50 \\
\hline Percentual de Abertura na Fachada Total (PAFt) & 0,40 \\
\hline
\end{tabular}

Após obtenção de todas as variáveis da equação, o índice de Consumo alcançado para a envoltória desta edificação foi $I C_{e n v}=23,62$.

\subsection{3. Índices de Consumo Máximo e Mínimo ( $I C_{\max } \bar{E}\left(C_{\min }\right)$}

A determinação dos limites de eficiência da envoltória é realizada através dos $I C_{\max } \mathrm{e}$ $I C_{\min }$. Para tanto, é necessário calcular estes valores. Este cálculo é efetuado usando a mesma equação do $I C_{\text {env }}$ e com os dados de Fator de Forma e Fator Altura da edificação. Já os dados PAFT, FS, AVS, AHS utilizados são alterados, conforme o Regulamento. Os parâmetros obtidos da edificação analisada e os utilizados para cálculo do $I C_{\max }$ e $I C_{m i n}$, podem ser visualizados na Tabela 8:

Tabela 8: Parâmetros para cálculo de IC

\begin{tabular}{ccccc}
\hline & PAF & FS & AVS & AHS \\
\hline$I C_{\text {env }}$ & 0,4 & 0,5 & 45 & 24,12 \\
$I C_{\text {max }}$ & 0,6 & 0,61 & 0 & 0 \\
$I C_{\text {min }}$ & 0,05 & 0,87 & 0 & 0 \\
\hline
\end{tabular}

O resultado obtido do $I C_{\max }$ foi 37,11 , o que representa o indicador de consumo máximo para a volumetria da edificação. Já o resultado do $I C_{\text {mín }}$ foi 17,14 , representando o indicador de consumo mínimo para volumetria da edificação.

Com estes limites de $I C_{\max } \square$ e $I C_{\operatorname{minn}}$ criou-se um intervalo dentro do qual a edificação se inseriu. $O$ intervalo é dividido em 4 partes (i), cada parte se refere a um nível de classificação numa escala de desempenho que varia de $A$ a E. A subdivisão i do intervalo foi calculada pela Equação 05, apresentando resultado final de 4,99.

$$
\mathrm{i}=\frac{I C_{\max }-I C_{\min }}{4}
$$

O valor encontrado de i foi utilizado para preencher as equações da Tabela 9, para definição de limites de intervalos dos níveis de eficiência. Os limites definidos para esta edificação podem ser visualizados na Tabela 10. 
Tabela 9: Limites dos intervalos dos níveis de eficiência

\begin{tabular}{|c|c|c|c|c|c|}
\hline Eficiência & A & B & C & D & E \\
\hline Lim Mín & - & $I C_{\max }=-3 \mathrm{i}+0,01$ & $I C_{\max }-2 \mathrm{i}+0,01$ & $I C_{\max }=-\mathrm{i}+0,01$ & $I C_{\max }+0,01$ \\
\hline Lim Máx & $I C_{\max }=-3 \mathrm{i}$ & $I C_{\max }-2 \mathrm{i}$ & $I C_{\text {max }}-i$ & $I C_{\max }$ & 10 \\
\hline
\end{tabular}

Tabela 10: Limites dos intervalos dos níveis de eficiência calculados para a edificação

\begin{tabular}{lccccc}
\hline Eficiência & A & B & C & D & E \\
\hline Lim. Mín. & - & 22,14 & 27,13 & 32,13 & 37,10 \\
Lim. Máx. & 22,13 & 27,12 & 32,12 & 37,11 & - \\
\hline
\end{tabular}

\subsubsection{Determinação da Eficiência da Envoltóriaf}

$O$ edifício analisado, segundo metodologia do método prescritivo do RTQ-C (PROCEL 2010), atingiu nível de classificação B quanto à eficiência da envoltória. Este valor foi obtido conforme cálculo de $I C_{e n v}$ e dos limites de intervalo calculado dos níveis de eficiência. 0 resultado obtido foi $B$, mas, para tanto, foi necessário o cumprimento dos pré-requisitos gerais e específicos para nível $B$ fossem cumpridos, o que ocorreu. Portanto, o nível obtido foi realmente B, como mostra a Figura 25.

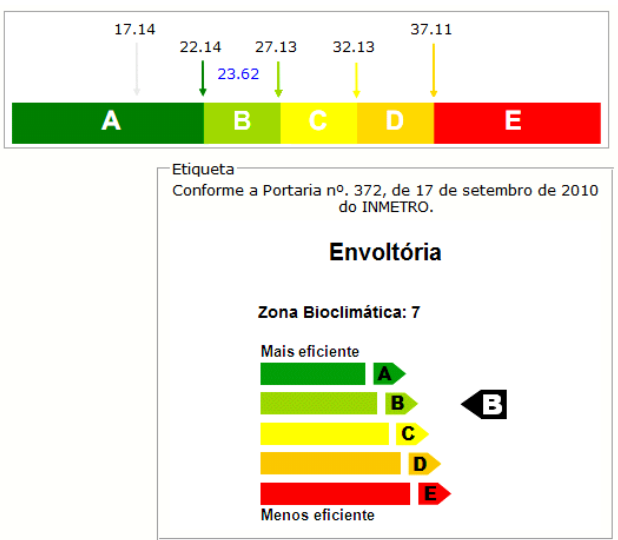

Figura 25: Nível de Eficiência da Edificação Analisada

Fonte: http://www.labeee.ufsc.br/sites/default/files/webprescritivo

\section{CONSIDERAÇÕES FINAIS}

As medições de Temperatura in loco mostraram que o sistema de refrigeração mantém a temperatura praticamente constante, variando, durante todo o tempo de medição de apenas 24 a $27{ }^{\circ} \mathrm{C}$. Sendo que as temperaturas mais altas, como $36^{\circ} \mathrm{C}$ foram alcançadas apenas em horários fora de expediente, quando os condicionadores de ar eram desligados, como nos finais de semana durante o dia, entretanto, estas medições fora de expediente não foram apresentadas neste artigo. Analisando tanto pelo método de Fanger (PMV e PPD) quanto pela carta bioclimática de Givoni, as médias de temperatura durante o horário de expediente estão dentro da faixa de conforto térmico, apresentando mínimos percentuais de pessoas insatisfeitas por calor. $O$ único ambiente que apresentou dados diferenciados foi o ambiente 6 , mas isso devido ao período de 
sua medição, já dentro da estação quente e seca, no mês de agosto, onde, geralmente, são alcançados os maiores valores de temperatura e menores de umidade na cidade de Cuiabá, MT.

Com relação ao nível do pavimento, salas no térreo, primeiro ou segundo pavimento não apresentou variação entre seus valores, verificando que este fator não influenciou os resultados. No que diz respeito à orientação solar dos ambientes, pôde-se observar que os que possuíam sua parede voltada para Oeste obtiveram valores de temperatura um pouco superiores aos valores dos ambientes voltados para a fachada Leste.

A análise da envoltória da edificação seguindo parâmetros e diretrizes do RTQ-C obteve um bom resultado, pois o nível $B$ de eficiência a edificação já é considerada eficiente, com menores cargas térmicas internas, permitindo que o sistema de refrigeração artificial não necessite um alto consumo de energia para proporcionar um ambiente confortável termicamente. Para obtenção do nível $A$, seria necessária a aplicação de algum tipo de isolamento térmico na cobertura, de forma a diminuir sua transmitância (pré-requisito para nível A) ou até mesmo a troca do material da cobertura.

\section{REFERÊNCIAS BIBLIOGRÁFICAS}

\section{ASSOCIAÇÃO BRASILEIRA DE NORMAS TÉCNICAS - NBR 15220-3/2005 - Desempenho Térmico de}

Edificações (Parte 3: Zoneamento Bioclimático Brasileiro e Diretrizes Construtivas para Habitações

Unifamiliares de Interesse Social).

BARBOSA, M. J.; LAMBERTS, R.; GUTHS, S. Uso de barreiras de radiação para minimizar o erro no registro das temperaturas do ar em edificações. Revista Ambiente Construído, Porto Alegre, v. 8, n. 4, p. 117-136, out./dez. 2008.

BERALDO, J. C. Eficiência energética em edifícios: avaliação de uma proposta de regulamento de desempenho térmico para a arquitetura do estado de São Paulo. Universidade de São Paulo, São Paulo, 2006. (Dissertação de Mestrado).

FANGER, P. O. Thermal comfort: analysis and applications in environmental enginneering. New York: McGraw-Hill, 1972.

INTERNATIONAL ORGANIZATION FOR STANDARDIZATION (ISO). ISO 7730: Moderate Thermal Enviroments - Determination of the PMV and PPD indices and specification of the conditions for thermal confort.[S.I], 1984.

KLÜSENER, C. S. Aplicação Do Regulamento Técnico Da Qualidade Para Etiquetagem Do Nível De Eficiência Energética De Edifícios: O Caso Do Centro De Tecnologia Da UFSM. Santa Maria: UFSM, 2009.

(Dissertação de Mestrado) LAMBERTS, R.; DUTRA, L.; PEREIRA, F. O. R. (1997). Eficiência energética na arquitetura. 2 ed. São Paulo: ProLivros, 2004. 192p. 
LAMBERTS, R;NARANJO, A. Desempenho Térmico de Edificações. Florianópolis : Apostila - Universidade Federal de Santa Catarina, 2011.

LEÃO, E. B. Carta Bioclimática de Cuiabá. 2007.147 f. Dissertação. (Mestrado em Física e Meio Ambiente) Departamento de Física, Universidade Federal de Mato Grosso, Cuiabá, 2007.

MAGALHÃES, L. C. Orientações gerais para a conservação de energia elétrica em edifícios públicos. PROCEL, 2001.

NAVARINI, F. C., KLOSOWSKI, E. S., TORRES, A. C., ROCKENBACH, E. K., EYNG, C., LIMA M. Avaliação de Diferentes Diâmetros e Materiais para Confecção de Globos Negros para estimativa de índice de conforto térmico em condições de pasto.In: ASSOCIAÇÃO BRASILEIRA DE ZOOTECNISTAS, 2007, Brasília. Anais eletrônicos ..., Brasília: ABZ, 2007. Disponível em:<http://www.abz.org.br/publicacoes-tecnicas/anaiszootec/artigos cientificos/bioclimatologia-ambiencia>. Acesso em: 04 Mar.2011.

PEREIRA, N.; BOND, T. E.; MORRISON, S. R. Ping-pong ball into black-globe thermometer. Agricultural Engineering, St. Joseph, v.10, n.48, p.341-342, Jun. 1967.

PROCEL - PROGRAMA NACIONAL de CONSERVAÇÃO de ENERGIA ELETRICA Manual para Aplicação dos Regulamentos: RTQ-C e RAC-C. Rio de Janeiro: Procel/Eletrobras, 2010. Disponível em: <http://www.labeee.ufsc.br/eletrobras/etiquetagem/downloads.php>. Acesso em:.14/06/2011. Regulamento Técnico da Qualidade para o Nível de Eficiência Energética de Edifícios Comerciais, de Serviços e Públicos (RTQ-C). Rio de Janeiro: Procel/Eletrobras, 2010. Disponível em: <http://www.labeee.ufsc.br/eletrobras/etiquetagem/downloads.php>. Acesso em:.14/06/2011. ROMERO, B. M. A. A arquitetura bioclimática do espaço público. Brasília: Editora Universidade de Brasília, 2001.

SILVA, J. S. A eficiência do brise-soleil em edifícios públicos de escritórios: estudo de casos no plano piloto de Brasília. Brasília: UNB, 2007. (Dissertação de mestrado)

SOUZA, C.F.; TINÔCO, I.F.R.; BAÊTA, F.C.; FERREIRA, W.P.M.; SILVA, R.S. Avaliação de materiais alternativos para confecção do termômetro de globo. Revista Ciência e Agrotecnologia. Lavras, v.26, n.1, p.157-164, jan./fev., 2002. Disponível em: $<$ http://www.editora.ufla.br/site/index.php?id=100\&menu=m9 $>$ Acesso em: 04 de mar.2011. 